Special issue of the 3rd International Conference on Computational and Experimental Science and Engineering (ICCESEN 2016)

\title{
K-Ar Dating for Determining the Age of Mineralization as Alteration Product: A Case Study of Antimony Mineralization Vein Type in Granitic Rocks of Gümüşhane Area, Turkey
}

\author{
A. VURAL* \\ Gümüşhane University, Faculty of Engineering and Natural Sciences, Department of Geological Engineering, \\ Gümüşhane, Turkey
}

\begin{abstract}
Is it feasible to use K-Ar dating method in determination of the age of mineralization by utilizing alteration minerals? The purpose of this study was to examine the utility of the K-Ar dating method to accurately determine the age of mineralization. In ideal circumstances, dating of alteration products, such as illite and serisite minerals, gives the age of alteration event, which is indirectly associated with mineralization. In the study site, referred to as Avliyana, antimony mineralization (Gümüşane, Turkey), stibnite (antimony) mineralizations of hydrothermal vein type were observed in granitic young intrusive rocks and the host rocks. In the study area, alteration was observed in the form of a small amount of weak silicification, argillitization (sericitization and illitization), hematitization, limonitization close to the mineralization and of epidotization and chloritization far from the mineralization. In order to determine the limits of the age of antimony mineralizations of the area, the K-Ar method was used to date illite and serisite minerals, which are alteration products related to mineralization. Two samples containing sericite and illite were collected from Avliyana antimonite mineralization. The alteration origin of these minerals was confirmed by supporting petrographic, XRD and scanning electron microscope studies. These samples were analysed for K-Ar dating.
\end{abstract}

DOI: 10.12693/APhysPolA.132.792

PACS/topics: 83.80.Nb, 91.67.Qr

\section{Introduction}

Potassium is a radioactive element which is one of the eight most abundant elements in the Earth's crust and a major constituent of many rock-forming minerals. Soon after the discovery of radioactive potassium, the K-Ar dating technique was one of the earliest isotope dating techniques. Radioactive potassium is easily detectable and its half-life is ideal for dating geological events (1248 million years), making $\mathrm{K}-\mathrm{Ar}$ dating technique the most popular isotopic dating technique. It can be theoretically applied in a range from the early Precambrian through the Holocene. Aldrich and Nier [1] first demonstrated that ${ }^{40} \mathrm{Ar}$ was the product of the decay of ${ }^{40} \mathrm{~K}$, and soon after, K-Ar dating method had begun to be used for geological dating in several laboratories.

As the details can be found in Kelley [2-4], the "date" measured by K-Ar and other techniques (i.e. Ar-Ar) reflects the time since radiogenic argon produced by decay of ${ }^{40} \mathrm{~K}$ becomes trapped in the mineral or rock. This may be the "age" of the rock or the most recent geological event and in some samples may even reflect an integrated cooling age for a range of sub-grains. There must be some preliminary assumptions in radiometric dating that must be valid if the number measured is to be interpreted as the age of a geological event $[2,5]$ :

\footnotetext{
*e-mail: alaaddinvural@hotmail.com
}

1. The decay of potassium must be independent of its physical state.

2. At any given time, the ${ }^{40} \mathrm{~K} / \mathrm{K}$ ratio must be a constant.

3. All radiogenic ${ }^{40} \mathrm{Ar}$, measured in the investigated sample, results from ${ }^{40} \mathrm{~K}$ decay.

4. The sample, whether mineral or whole rock, must have remained a closed system since the event being dated.

Potassium is chemically incorporated into common minerals, especially in hornblende, biotite and potassium feldspar, which are component minerals of igneous rocks, and in muscovite, sericite, illite, which are component minerals of hydrothermally altered products [6-10]. Since argon is an inert gas, it cannot combine chemically with anything, so just after minerals have formed there is not much argon in igneous rocks. This makes it useful for dating some special geological events. If the assumption that there was no argon in the rock originally is correct, then all the argon in it now must have been produced by the decay of ${ }^{40} \mathrm{~K}$. So what has to be done is to measure the amount of ${ }^{40} \mathrm{~K}$ and ${ }^{40} \mathrm{Ar}$ in the mineral and calculate how long ago the geological structures were formed, since the decay rate of ${ }^{40} \mathrm{~K}$ is known. From the equation describing radioactive decay, the following equation can be derived: 


$$
t=h \log _{2}(1+R / c),
$$

where $t$ is the age of the event in years, $h$ is the half-life of ${ }^{40} \mathrm{~K}$ in years, $c$ is the proportion of ${ }^{40} \mathrm{~K}$ which decays to ${ }^{40} \mathrm{Ar}$ rather than to ${ }^{40} \mathrm{Ca}$ (about $10.9 \%$ ) and $R$ is the measured ratio of ${ }^{40} \mathrm{Ar}$ to ${ }^{40} \mathrm{~K}$.

\section{Materials and methods}

\subsection{Framework of the study}

There is no study on the mineralization age of the antimony mineralization (AM) in Gümüşhane (Fig. 1a) in the literature. As mentioned earlier, $\mathrm{K} / \mathrm{Ar}$ dating method depending of alteration minerals can examine the age of mineralization. Dating of alteration products such as illite and sericite minerals gives the ages of alteration event, which itself is a mineralization age. In the study, in order to determine the limits of the age of AM of the area, the K-Ar method was used to date illite

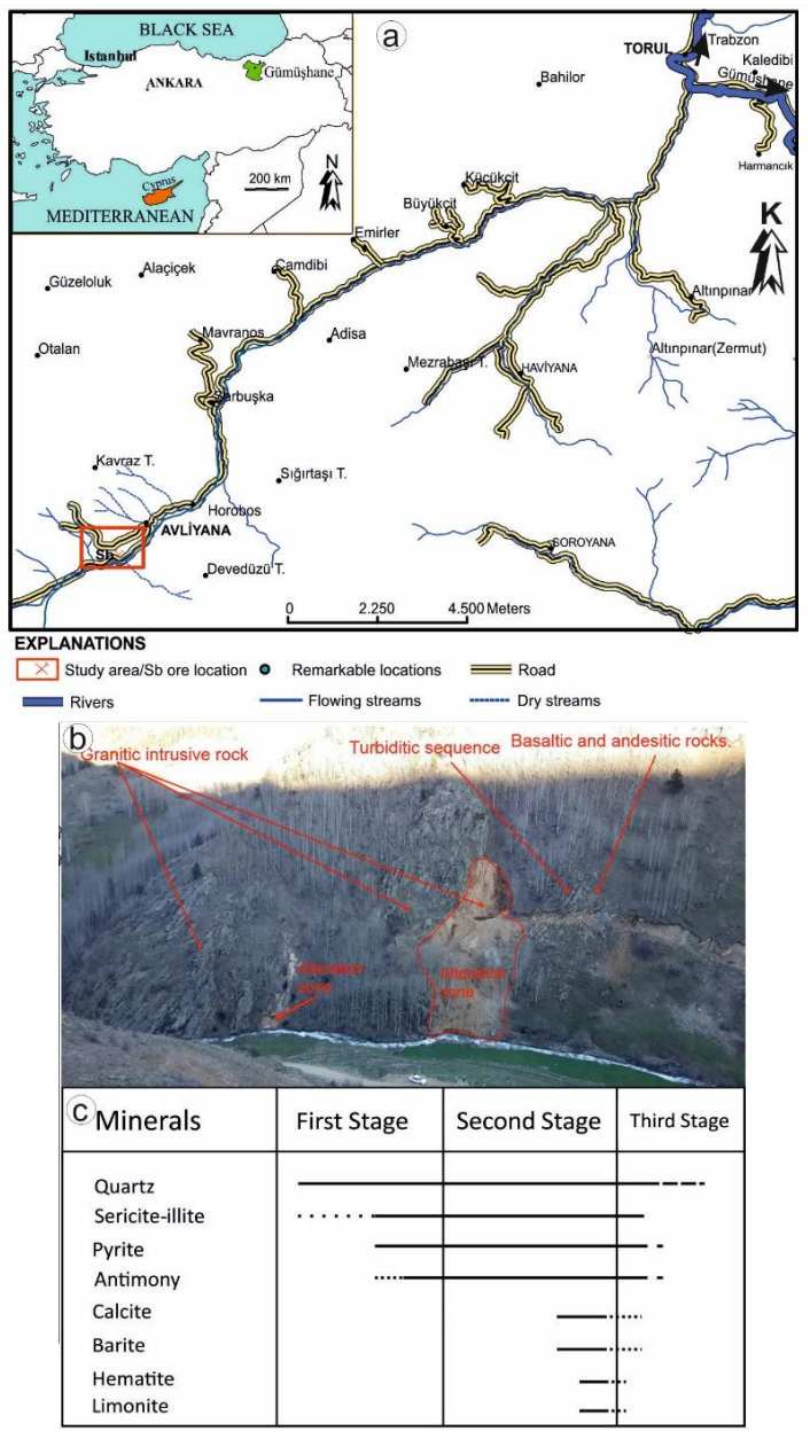

Fig. 1. Location map (a), photograph of the mineralizations (b), and succession stage of the mineralization (c). and sericite minerals, which are alteration products related to mineralization. In the area, AM was of hydrothermal vein type in the granitic intrusive rock and its host rocks, which dominantly consist of turbiditic sequence, containing basaltic and andesitic rocks [11] (Fig. 1b). On the basis of the paragenetic sequences of minerals, ore petrography and crosscutting relationships, the ore-forming process can be divided into three stages (Fig. 1c)

Namely, first stage corresponds to thin quartz veins or replacement with or without pyrite and antimony, second stage corresponds to dominant sericitization, pyrite and antimony mineralization, and third stage corresponds to common oxidation minerals, such as hematite, limonite etc. Abundant pyrite, antimony, quartz form in the second stage. Three stage fluid-rock interactions result in wallrock alteration, mainly including silicification, sericitization and illitization, hematization, limonitization near the mineralization and carbonatization, epidotization and chloritization far from the mineralization.

\subsection{Sampling and analytical methods}

In order to determine the limits of the age of antimony mineralizations of the area, the K-Ar method was used to date illite and sericite minerals, which are alteration products related to mineralization. For K-Ar analysis, two samples containing mineral sericite and illite were collected from alteration products at AAM. These are creamy-white chalky alteration products, which occurred in hydrothermal vein and veinlets. Sampling was carried out taking into account the field recognition of alteration zone and the three-stage evolution of the mineralization. The alteration origin of these minerals was confirmed by supporting petrographic, XRD and SEM studies. These samples were sent to Geochronex analytical services and consulting laboratory (Canada) for further sample preparation and analysing. Mineral purification and separation were performed for two samples. The separated fraction for one of samples was checked by SEM and 60$70 \%$ quatz, $35 \%$ illite and $<5 \%$ feldspar, plus minor iron and titanium minerals were determined. The separated fraction for other one was confirmed by SEM as mineral sericite.

During the $\mathrm{K}$ analysis, the laboratory procedure was as follows: aliquot of the sample was weighed into graphite crucible with lithium metaborate/tetraborate flux and fussed using LECO induction furnace. The fusion bead was dissolved with acid. Standards, blanks and sample were also analysed in ICP Spectrometer.

During Ar analysis; aliquot of the sample was weighed into $\mathrm{Al}$ container, loaded into sample system of extraction unit, degassed at $\sim 100{ }^{\circ} \mathrm{C}$ during two days to remove the surface gases. Argon is extracted from the sample in double vacuum furnace at $1700^{\circ} \mathrm{C}$. Argon concentration was determined using isotope dilution with ${ }^{38} \mathrm{Ar}$ spike, which was introduced into the sample system prior to each extraction. The extracted gas was cleaned up in two step purification system. 
Then pure Ar was introduced into custom built magnetic sector mass spectrometer (Reynolds type) with Varian CH5 magnet. The ion source has an axial design (Baur-Signer source), which provides more than $90 \%$ transmission and extremely small isotopic massdiscrimination. Measurement of Ar isotope ratios was corrected for mass-discrimination and then atmospheric argon was deducted. Concentration of radiogenic ${ }^{40} \mathrm{Ar}$ was calculated by using ${ }^{38} \mathrm{Ar}$ spike. After each analysis, extraction temperature was elevated to $1800^{\circ} \mathrm{C}$ for a few minutes and furnace was prepared for the next analysis.

\section{Results and discussion}

$\mathrm{K}$-Ar dating analysis of illite and sericite minerals related to AAM has revealed that the ages of these alteration products were $46.5 \pm 2.4$ and $49.0 \pm 2.6 \mathrm{Ma}$ with 2 standard deviations, respectively. Therefore, K-Ar dating of the minerals indicates that alteration had begun about $46 \mathrm{Ma}$ ago and possibly soon after the initiation of alteration, AM began with alteration process. In addition, these ages are consistent with granitic intrusion related to mineralization - its age was determined using SHRIMP II with U-Pb isotope study by Vural [12].

\section{TABLE I}

Results of K-Ar analysis, based on sericite and illite minerals, of alteration production related to the mineralization.

\begin{tabular}{|c|c|c|c|c|c|c|c|}
\hline Number & Features & $\% \mathrm{~K}$ & $\begin{array}{c}{ }^{40} \mathrm{Ar} \mathrm{rad}, \\
{[\mathrm{nl} / \mathrm{g}]}\end{array}$ & $\begin{array}{c}\%^{40} \mathrm{Ar} \\
\text { air }\end{array}$ & $\begin{array}{l}\text { Age } \\
\text { [MA] }\end{array}$ & \begin{tabular}{|c|}
$\sigma$ \\
error
\end{tabular} & $\begin{array}{c}2 \sigma \\
\text { erorr }\end{array}$ \\
\hline & & 1.46 & 2.624 & 28.6 & 46.5 & 1.2 & 2.4 \\
\hline TAM-15 & $\begin{array}{c}\text { Alteration } \\
\text { Minerals }\end{array}$ & 5.11 & 9.668 & 51.4 & 49.0 & 1.3 & 2.6 \\
\hline
\end{tabular}

\subsection{Limitations-withdrawals of $K$-Ar dating method}

- There are some limitations of the method used in this study. One is that if the rocks are recent, the amount of ${ }^{40} \mathrm{Ar}$ in them will be small and out of detection range of the instrument, and a rock formed recently will look no different from a rock formed a hundred thousand years ago. The severity of this problem decreases as the accuracy of the instruments increases. But still, as a general rule, the proportional error in $\mathrm{K}$-Ar dating will be important in the recently formed rocks. In this study, alteration age of $40-50 \mathrm{Ma}$ was outside of this limitation.

- A second problem is that for technical reasons, the measurements of argon and potassium have to be made on two different samples, since each measurement requires the destruction of the sample. If the mineral composition of the two samples is different, then this will be a source of error. However, laboratory facilities have been recently improved to compensate such error sources.
- Another concern with K-Ar dating is that it relies on there being no ${ }^{40} \mathrm{Ar}$ in the rock or mineral when it was originally formed, or added to it between its formation and the application of the K-Ar method. Because argon is inert, it cannot be chemically incorporated in the minerals when they are formed, but it can be physically trapped in the rocks either during or after formation. Such argon is known as excess argon. In this case, alteration products are the end products of the process and they could be affected as little as possible from excess argon. In addition, alteration age related to mineralization and age of granitic rock are compatible in this study.

- Some argon in the samples may come from the atmosphere, which may deteriorate the quality of data, however, in case this is true, the atmospheric correction was performed. If the argon came from deep within the Earth, where it was formed by ${ }^{40} \mathrm{~K}$ decay, and was then trapped in magma or transported into the rock by hydrothermal fluid, then the excess argon will not have the same ${ }^{40} \mathrm{Ar} /{ }^{39} \mathrm{Ar}$ ratio as is found in the atmosphere, and the formula that corrects for atmospheric argon will not correct for this.

Another concern is the possibility of argon loss. When a rock undergoes metamorphism, metasomatism or hydrothermal alteration, some or all of its argon can be outgassed. If all the argon was lost, this would reset the $\mathrm{K}$-Ar clock to zero, and dating the rock would give us the time of metamorphism, metasomatism or hydrothermal alteration. It precisely describes the current situation. However, it was thought that all the argon was not lost, and if so, it is said that K-Ar dating will give us an essentially arbitrary date somewhere between the formation/intrusion of the granitic rock, causing alteration, and the alteration event. This situation does not negatively affect our expectations for dating mineralization.

As known, alteration process is an open system. When alteration products occurred, geochronological clock was reset and new time began during the occurrence of end products, e.g. alteration and also mineralization. Thus, $\mathrm{K}$-Ar dating method was used for determination of age of mineralizations which are commonly related to alteration. When alteration minerals such as illite, serizite have occurred, the K-Ar clock was reset to zero, and dating the altered products would give us the time of alteration, indirect mineralization anyway.

\subsection{Relationship between mineralization age and geological setting}

According to Kaygusuz et al. [13], who conducted a study near the study-area mentioned in the current paper, the Cretaceous to Paleocene plutonic rocks in 
the eastern Pontides are dominantly $142-56 \mathrm{Ma}$ in age, while a major peak of igneous activity occurred around $\sim 78 \mathrm{Ma}$. The Eocene intrusive rocks are dominantly 53-29 $\mathrm{Ma}$ in age, with a major igneous event occurring around $\sim 42 \mathrm{Ma}$. While the older plutons were generated during subduction, the younger ones can be related to the collision of the eastern Pontide island arc with the Anatolide-Tauride plate during the Paleocene to Early Eocene, and subsequent regional extension.

Mineralization age from K-Ar (about $46 \mathrm{Ma}$ ) corresponds to the Early Eocene time. During Late Paleocene to Early Eocene time, in the Eastern Pontides, the initial stage of crustal thinning was caused by crustal extensional events. So, the antimony mineralization had occurred as vein and veinlet, depending on plutonic rock, which intruded, depending on the extensional event in the region.

\section{Conclusions}

$\mathrm{K}$-Ar dating method for determining mineralization age can be used when working with appropriate alteration minerals, related to mineralization. Since this method is also economical and allows fast analysis, it is preferable to other techniques.

\section{Acknowledgments}

This study is supported by TÜBİTAK (Grant Number: 113Y382). The author would like to thank Sebahattin Güner (General Directorate of Mineral Research and Exploration, MTA) for sharing his experiences about the area.

\section{References}

[1] L. Aldrich, A. Nier, Phys. Rev. 74, 876 (1948).

[2] S. Kelley, Rev. Mineral. Geochemistry 47, 785 (2002).

[3] İ. Akkurt, R.B. Ermiş, P. Baş, K. Günoğlu, Acta Phys. Pol. A 128, B-34 (2015).

[4] M.C. Boz, F. Öner, B. Mavi, Acta Phys. Pol. A 128, B-360 (2015).

[5] F. Ertuğral, H. Yakut, E. Tabar, R. Akkaya, N. Demirci, Z. Zenginerler, Acta Phys. Pol. A 128, B-251 (2015).

[6] N. Zaim, A.B. Tugrul, H. Atlas, B. Buyuk, E. Demir, N. Baydogan, N. Altinsoy, Acta Phys. Pol. A 130, 64 (2016).

[7] M. El Tokhi, B. El Din Mahmoud Amin, H. Arman, Acta Phys. Pol. A 130, 17 (2016).

[8] A. Coskun, B. Çetin, Acta Phys. Pol. A 130, 309 (2016).

[9] N.A. Uyanık, Z. Öncü O. Uyanık, M. Bozcu, İ. Akkurt, K. Günoğlu, F. Yağmurlu, Acta Phys. Pol. A 128, B-438 (2015).

[10] B. Mavi, I. Akkurt, Rad. Phys. Chem. 79, 933 (2010).

[11] A. Vural, Acta Phys. Pol. A 130, 191 (2016).

[12] A. Vural, Avliyana (Torul-Gümüşhane) Antimonit Cevherleşmesinin Jeolojisi-Mineralojisi ve Kökeninin Araştırılması, Tubitak Project Report (Grant no: 11Y382), 2016.

[13] A. Kaygusuz, W. Siebel, N. Ilbeyli, M. Arslan, M. Satır, C. Şen, J. Mineralogy Geochem. 187, 265 (2010). 